Article

\title{
Youth for Sale: Using Critical Disability Perspectives to Examine the Embodiment of 'Youth'
}

\section{Jenny Slater}

Room 10110, Arundel Building, Sheffield Hallam University, 122 Charles Street, Sheffield, South Yorkshire S1 2NE, UK; E-Mail: J.Slater@shu.ac.uk; Tel.: +44-114-255-6691

Received: 26 October 2011; in revised form: 22 August 2012 / Accepted: 30 August 2012 /

Published: 13 September 2012

\begin{abstract}
Youth' is more complicated than an age-bound period of life; although implicitly paired with developmentalism, youth is surrounded by contradictory discourses. In other work [1], I have asserted that young people are demonized as risky and rebellious, whilst simultaneously criticized for being lazy and apathetic; two intertwining, yet conflicting discourses meaning that young people's here-and-now experiences take a backseat to a focus on reaching idealized, neoliberal adulthood [2]. Critical examination of adulthood ideals, however, shows us that 'youthfulness' is itself presented as a goal of adulthood [3-5], as there is a desire, as adults, to remain forever young [6]. As Blatterer puts it, the ideal is to be "adult and youthful but not adolescent" ([3], p. 74). This paper attempts to untangle some of the youth/adult confusion by asking how the aspiration/expectation of a youthful body plays out in the embodied lives of young dis/abled people. To do this, I use a feminist-disability lens to consider youth in an abstracted form, not as a life-stage, but as the end goal of an aesthetic project of the self that we are all (to differing degrees) encouraged to set out upon.
\end{abstract}

Keywords: youth; disability; feminist; feminist-disability; embodiment; time; crip time; sociology of childhood; commodification

\section{Introduction}

Feminist scholars have highlighted the self-governing expectation placed upon women to perform 'bodywork' in order to meet up to an ideal of bodily perfection [7]. One of the aims of such bodywork is to retain a 'youthful' body [6,8]. Youth is abstracted from the lived, embodied, experiences of young people's lives to be sold as a commodity through beautification products aimed at prolonging 
'youthful' looks. The body becomes an aesthetic project, and youth a desirable outcome. Considering 'youth' as the outcome of an aesthetic project tears it away from discourses of age we familiarly associate it with; we see it has been commodified, made into a thing-like form, which is available for cross-generational consumption. Mallet and Runswick-Cole [9] utilize theories of commodification in relation to autism. They argue that autism has been fetishised (a Marxist concept of making something a thing by distancing a product from its labors), and attribute the prevalence of autism, both within popular culture and academic research, to this process of fetishisation. They explore this by asking three questions: who produces autism? What want is autism satisfying? And what is the promise of autism? According to dominant developmental theory, unlike autism, youth is a stage we all pass through and embody for a period of our lives [10]. However, youth stands for much more than just an age-bound period of life [1-3] and hence, it is not immune from fetishisation and commodification [11,12]. I therefore relate these questions to youth as a backdrop to this paper, asking: who produces the 'youth-for-sale-thing'? And what want is this youth-for-sale-thing promising to satisfy when we buy into it?

The paper takes an intersectional and transdisciplinary approach, yet, as a researcher grounded in Critical Disability Studies (CDS), a CDS perspective is my primary conceptual lens to examine the concept of 'youth for sale'. I begin by offering an overview of feminist-disability theory. Feminist and feminist-disability scholars see the pressure to remain 'youthful' as problematic. However, there is little critical engagement as to what we expect of, or mean by, 'youthful' looks, what we aspire to in our quest for 'eternal youth', and how this relates to the lived-realities of young people's lives. In other words, there is little attempt to answer what want youth is promising to satisfy. A feminist-disability perspective is useful here as the lives of disabled young people arguably magnify the process of abstraction (see also [13]). I will utilize feminist-disability theory to interrogate notions of the idealized body and explore attempts to question notions of beauty within the popular media. Due to the intersectional nature of the paper, it may feel at times that 'youth' has been lost from discussion. I ask the reader to bear with this, as it is from here we see that although the ideal body may always be young, the young body is not always ideal.

I will go on to consider what else we are searching for when we aspire to remain (aesthetically) youthful. Featherstone [8] argues that the aged body is inscribed with the passing of time, and we attempt to deny this in our attempts to look young. I will unpack this further by exploring notions of time more closely, engaging in both CDS discussions of 'crip time' and literature from the sociology of childhood which considers children's understandings of time. Both schools of thought see embodiment as key to our conceptions of time, and I will draw on these to argue that the aesthetic project of youth not only links youth with beauty, but also with health. Health and beauty, I will pose, are perhaps the want and promise of youth.

\section{Feminist-Disability Theory}

Uncovering the notion of youth as an aesthetic project begins with recognizing the body as discursive and culturally inscribed with meaning [6,14-16]. During the 1990s examining the consequences of bodily representations became central to feminist theory $[15,16]$. Scholars used feminist theory to explore the body in relation to gender, race, ethnicity, sexuality and class - asking 
how these intersections of identities allow some bodies to be regarded more highly than others [17]. However, despite the centrality of disability to experiences of embodiment $[18,19]$, how dis/ability played out in discourses of the body was an area neglected by feminist theorists [15]. This silence cannot be blamed entirely on lack of feminist engagement. British Disability Studies, with its staunch social model focus, separating impairment (a difference, or perceived difference, of bodily function) and disability (subsequent oppression placed on disabled people by society) prohibited talk of the body within Disability Studies [20]. This was not without reason, previous medical focus constructed the disabled body as deficient, in need of intervention, rehabilitation and, ultimately, extermination. Therefore, to remove the gaze from the disabled body and counter this by challenging an oppressive disabling society was crucial to the political struggle of disabled people. In addition, the lack of communication between feminist and disability theory could be attributed to the pragmatism that few disability theorists 'knew' feminist theory and few feminist theorists 'knew' disability theory [15].

A CDS approach, however, has meant the body, and experiences of embodiment, have begun to re-enter discussions. Much of this can be attributed to the voices of disabled women highlighting the lack of space available for them within both feminist and disability movements [20-23], and therefore carving the way for feminist-disability theory. Whereas feminist theory has forced us to re-examine the assumptions we make about women, and disability theory has challenged individual notions of disability, feminist-disability theory brings the two together, not additively, but alongside further intersections of race, class, sexuality, and so on [15]. Within feminist-disability theory, disability, like gender, is seen as a phenomenon that spans all aspects of life. Thus, feminist-disability theory does not only address issues directly concerning disability, but can be used as a lens to critically engage with wider cultural phenomenon. As Garland-Thomson ([15], p. 4) puts it, "the cultural function of the disabled figure is to act as a synecdoche for all forms that culture deems non-normative", consequently, feminist-disability theory can help us critically challenge what may at first appear 'natural'. Adding disability to the intersectional work already done by feminist scholars adds depth to a critique of idealized bodies.

\section{Cultural Representation}

Writing in 1997, Shakespeare [19] argues that Disability Studies engagement with cultural representations of disability is relatively new. Since Shakespeare's writing, Disability Studies has emerged within Cultural Studies departments. An overt engagement with cultural representations of 'youth', however, is rare [13]. Although Youth Subcultural Studies addressed the symbolic in relation to youth [24], the discipline failed to incorporate an analysis of disability. Hughes, Russel and Patterson [13] highlight that disciplines such as Youth Subcultural Studies assume a fluidity of identity, available to young people through buying into 'youth cultures'; an engagement many young disabled people are denied through material, attitudinal, and I would add psycho-emotional, disablism [25].

Titchkosky ([26], p. 518) writes that "to know how disability is produced as a problem in need of remedy [...] is to come to know how and why disability matters". Additionally, Kumari-Campbell [27] argues we must theorize the able-body, in order to understand processes of disablism. Drawing on both these arguments I argue that feminist cultural explorations which consider cultural representations of 
idealized bodies can help us understand "how disability is produced as a problem" ([26], p. 518) in relation to discourses of youth and adulthood. I now turn to theoretically analyze media representations of aesthetics, beauty and disability in relation to a pedestalled ideal. I will go on to incorporate youth into this analysis, in order to ponder what 'youth for sale' means for dis/abled youth not considered under this umbrella.

\section{Idealized Bodies: Questions and Challenges}

Feminist critiques of idealized body image are nothing new. Scholars have argued that the pervasiveness of media idealized body images have allowed the unattainable to become a normal standard of acceptable beauty [7,15,28,29]. This has resulted in an ethos of personal responsibility; there is an expectation on the individual to discipline their body [7,8]. In Discipline and Punish, Foucault [30] theorizes self-disciplinary practices. He argues that the nineteenth century saw a shift from sovereign power, demonstrated through public torture and execution, to a disciplinary power. Rather than acting top-down, disciplinary power permeates day-to-day living, acting through and performed by individuals, whom Foucault terms 'vehicles of power'. Furthermore, power and knowledge, Foucault maintains, are inseparable, and result in discourses and norms which bodies are judged against. As 'vehicles of power', no individual is outside systems of power-knowledge, rather the system (which he describes as carceral and Panoptic) creates docile bodies; gazing upon the bodies of others whilst simultaneously surveying themselves. Featherstone [8] and Turner [31] argue that discourses of dietary management illustrate such 'disciplining technology', encouraging an ethos of self-discipline in order to comply with expected bodily standards.

Studies have shown the negative impact images of 'bodily perfection' have on women and girls, attributing the prevalence of anorexia and bulimia, for example, to the pressure to conform to unattainable bodily ideals [32,33]. As the literature points out, youth is a commonly recurring feature of the idealized body [6], something that becomes anecdotally apparent when considering the number of products available on the market claiming to prolong youthful looks, especially for women. Research has considered the aged experiences of living with images of 'bodily perfection'. Scholars have looked at the impact of idealized body images on young people, both female and male [34-37]. Furthermore, the invisibility of older people within the advertisement industry has been noted [38]. The mainstream media, however, has recently insisted that the trend for idealized 'youthful' beauty is fading. An article appearing in The Guardian in 2010 noted the rise in older models, claiming in its opening line, "the fashion industry is over its obsession with youth" [39]. The Guardian is not unique in now hosting a fashion column in its Saturday magazine supplement sporting 'all ages' models. Furthermore, popular make-over television shows such as, How to Look Good Naked, a program claiming to show "women how to look fantastic with their clothes on or off no matter what their body shape - and all without a surgeon's scalpel in sight" [40], have been uncritically accredited within the popular media with challenging notions of idealized feminine beauty and lessening pressure to comply to cosmetic surgery. The show's presenter, Gok Wan, went to on endorse the UK strand of the Dove Campaign for Real Beauty, which, attributing the media as the main cause of bodily unhappiness, aimed to counter dominant notions of feminine beauty to "ensure that the next generation [of young 
women] grows up into happy and content adults, free from misconstrued beauty stereotypes and the burden of self-doubt" [41].

We can also point to examples of popular television reality shows aiming to bring disability into the realms of the 'beautiful'. 2009 saw Britain's Missing Top Model, a spin off Britain's Next Top Model (itself the British sister of an American counterpart), pit disabled women against each other in a bid to win a modeling contract. The following year, Channel 4 produced a spin off version of 'How to Look Good Naked', entitled, 'How to Look Good Naked... with a Difference', a series of three programs which subjected three disabled women to the public undressing and stylistic tips of presenter, Gok Wan. Most recently, in 2011, Channel 4 went on to produce Beauty and the Beast: The Ugly Face of Prejudice. This six part series, endorsed by the facial disfigurement charity, Changing Faces, attempted to "investigate the extremes of discrimination". Each episode brought together one 'beauty' (a person "preoccupied with their appearance") and one 'beast' (a person with a "facial disfigurement") in order to, somewhat unconvincingly, challenge dominant notions of beauty [42].

For all these series, disability was the hook, drawing us in by asking us to gaze upon the disabled body. When disability appears within our mainstream media without 'warning', or not as a 'feature', however, audience reception is less favorable. This became shockingly apparent when the BBC chose Cerrie Burnell, a disabled woman (young, attractive, and able to 'pass' as acceptable by most beauty standards if it was not for the 'missing' lower portion of her right arm), to present their children's television channel CBeebies, a move which resulted in complaints from parents claiming Burnell was "scaring their children" [43]. The same year, a 22-year-old shop-assistant sued designer fashion label Abercrombie and Fitch after they insisted she moved from working on the shop floor to the stockroom, claiming her prosthetic arm did not fit their image [44]. Furthermore, when US fashion magazine, Glamour, published a $7.5 \mathrm{~cm}$, un-airbrushed photograph of 'plus size' (yet young, attractive, blond, and with no visible impairment) model Lizzie Miller with a small roll of fat around her stomach, the generated media frenzy was phenomenal [45].

Out of the above examples, The Dove Campaign for Real Beauty is the only instance of a company specifically claiming to be working towards wider social change. As well as using women who would not meet conventional 'modeling standards' in their adverts, Dove also launched The Self-Esteem Fund and encouraged audiences to participate through interactive message boards. Heiss [6] uses feministdisability theory to engage with the campaign. She argues that Dove does not go far enough in its attempts to include a diverse range of female bodies, instead acting within "an ideology of naïve integration". That is, an ideology that rhetorically insists upon a respect for diversity, yet, in reality, results in tokenism; (re)inscribing dominant notions of the 'normal', 'beautiful' and idealized 'feminine' body. Not only does Dove not use a model with a visible impairment, those models that are used could 'pass' as traditional models, albeit for one feature. Heiss [6] maintains that the 'fat' model, for example, "hardly looked overweight" and, apart from grey hair and a few wrinkles on her face, the body of the 'older' model "could have been that of any typical fashion model and was unrepresentative of many women". Similar criticisms could be made of the shows cited above. The winner of Britain's Missing Top Model could have 'passed' as any other model if it was not for her 'missing' forearm (interestingly, although celebrated in this show, this is the same impairment that caused such controversy in relation to the children's television presenter when disability was not the 'hook'). Furthermore, Heiss [6] points out the campaign insisted that we looked at the women's bodies as 
"separate parts to be examined", rather than viewing the women holistically the models were separated by discrepancy from 'modeling standards': the 'old' model, the 'fat' model, the 'freckled' model, and so on. This, she insists, is dangerous:

"Because the campaign was situated as a safe place for social change, when the campaign suggested that women should gaze upon and evaluate the body it reified beliefs that objectifying the body is acceptable and natural" [6]

Heiss [6] argues that despite its claim of challenging the objectification of women, Dove is in fact reifying an objectifying gaze (although, as the academy is not outside of culture and systems of powerknowledge, statements about the 'fat' model "hardly look[ing] overweight" show Heiss to be compliant in this). Garland-Thomson [15] complicates arguments of objectification in relation to disability. She highlights that images of disabled people traditionally fall into four categories: charity advertisement, freak show exhibits, medical depictions or "sensational and forbidden pictures" ([15], p. 23). With disability comes an assumption of asexuality, therefore, the gaze placed upon disabled women is not one of (explicit) sexual objectification but one of medical spectacle. Disabled women, Garland-Thomson ([15], p. 24) argues, should be allowed the same "freedom to be appropriated by consumer culture" that non-disabled women have, even if this means increased sexual objectification, as, "to reject this paradoxical liberty is one thing; not to be granted it is another". She cites women being granted entrance into the military as a similarly "paradoxical liberty". This is not to dismiss Heiss' [6] important point that Dove does not go far enough in including a diverse range of female bodies. Nor is it a call to reject critical engagement with such imagery. Rather, Garland-Thomson's [15] analysis highlights the additional level of scrutiny a feminist-disability perspective allows for; whereas a purely feminist analysis may dismiss programs such as Britain's Missing Top Model as reifying the sexual exploitation of women, a feminist-disability perspective considers the complex histories and intersections between gazed upon disabled and female bodies.

Interestingly, in Dove's campaign and the other non-disability specific texts which claim to challenge dominant discourses of beauty, there is an emphasis on the 'normal' or the 'average' woman replacing the 'spectacular' or 'extraordinary' model. Indeed, Heiss [6] herself points to the discrepancy between the weights of models compared to the "average female" and writes of "narrow representations [of bodies that] have led to individual and societal dissatisfaction with the actual lived bodies that comprise most of the public" (italics my own). This approach is perhaps justified as a way of re-appropriating what we view as 'normal'-discourses of beauty and medicine have worked together to make unmodified bodies appear unnatural and abnormal, whereas we consider those that have been surgically altered (whether this is through reconstructive or cosmetic surgery) as natural and normal $[7,15,28]$. Models, Soley-Beltran argues, act as a figurehead to these normalizing discourses of power-knowledge:

"By embodying alleged physical perfection and permanent self-confidence, models' images and public personas make us believe in the utopian possibility of avoiding the discredit and abjection that menaces many women for not conforming to aesthetic and behavioral norms ([28], p. 37).” 
Such images of 'perfection' lead us to falsely believe that hairless legs and flat stomachs are both 'natural' and 'normal' [6], and place an expectation on women to comply with these perceived norms. This perhaps explains the disproportionate interest when Glamour magazine chose to use a model with a stomach not meeting this modeling convention.

Conversely, despite supposed similar aims of challenging bodily ideals, when campaigns focus specifically on disability the discourse of 'normal' moves to one of 'difference' (as illustrated when the incorporation of disability sees How to Look Good Naked become How to Look Good Naked... With a Difference). We are no longer attempting to incorporate the bodies of 'normal' women, but the bodies of 'different' women into notions of beauty. The focus shifts from reclaiming normality to appreciating diversity. Soley-Beltran ([28], p. 40) adds further complexity to the debate when, drawing on both personal experience and empirical data, she writes that although on the one hand models are "a mechanism defining and regulating the normative standards of acceptable identity", there is also a 'fascination' surrounding them. As a result, she argues, models are at once "the object of envy" but also "alienated from [their] own image [and] considered unreal or intellectually handicapped [sic]” ([28], p. 40). Although she does not specifically use the term 'freak', Soley-Beltran's [28] discussion of feminine beauty hints at an 'enfreakment' of models-objectified, gazed upon, at once the objects envy and disgust, and their bodies 'read' as a signs of their intelligence [46]. Although arguably the beauty standards models embody have become a 'normal' part of society, the models that embody them are read as 'abnormal' - and judgments about their mind, made from the surface of their body. Other feminist theorists have recognized 'character' and 'state-of-mind' judgments are made from surveying the female body [47]. Furthermore, feminist-disability scholars have highlighted the additional gaze placed upon the bodies of disabled women (and, to a lesser extent, men). Shildrick [18] notes that although when the body is normative, Western discourse seperates mind and body as wholly separate entities, the mind privileged as free, rational and disembodied, when the body is marked as 'different' the mind is also considered 'damaged'. Such a reading of the body can result in infantalising disabled people, but also, following the logic of Soley-Beltran [28], all those whose bodies we consider 'different' - even if this is a difference we are encouraged to aspire to.

As 'youthfulness' is another expectation of the ideal body, youth becomes equated with bodily perfection, with hairless legs and flat stomachs; the aesthetic project of youth, therefore, is one of meeting modeling conventions; youth comes to stand for, the tall, the slim, the 'beautiful'. Youth is abstracted from the lived-realities of being young. Soley-Beltran's [28] argument, that there is both an envy and an 'enfreakment' of models, can here be applied to youth. Although youth is a desirable outcome of the aesthetic project we are encouraged to set out upon, this does not mean young people themselves are positioned as the 'ideal' [1]: Youth for Sale leads the enfreakment of non-normative youth, as although the ideal body is always young, the young body is not always ideal.

\section{The Ideal Body is always Young... but the Young Body is not always Ideal}

In concurrence with above discussion, Heiss writes:

"Scholars have found that images of the body often present idealized versions of feminine beauty - thin, tall, long legged, and always young." [6] 
However, although having a 'youthful' body is ideal, when used in this way, the terms 'young' and 'youthful' represent something very different to the lived-experiences of chronologically 'young' people, and contradictory to other discourses of youth [1]. When considering those chronologically young the emphasis is on temporality: youth is the period after childhood and prior to adulthood; a time of disruption, risk and rebellion; a time of laziness and apathy; a time it is desirable to 'grow out of' by meeting pedestalled adulthood signifiers [1]. Youth and time are intrinsically, yet incongruously linked: whereas, on the one hand, we want to assist young people in their risky transition to adulthood (the sooner they can reach it the better), there is also a desire to remain, as adults, forever young. Although when discussed explicitly youth is about transience, when discursively, perhaps implicitly used, youth is about the desire to pause time.

Time and embodiment are key features of our desire for eternal youth. Here I want to consider the relationship between time and embodiment further. In a neoliberal society, time is a valuable commodity. Christensen, James and Jenks [48] consider how children understand and embody time, arguing that children learn the 'value' of time through bodily discipline in the classroom: 'wasting' the teacher's curriculum time, leads to the teacher claiming back this time by denying the student playtime. Children learn that time is a finite resource, to be used productively: 'time is money', not something to be 'wasted', and, if used correctly, the reward may be 'free time', thus, according to the budget studies of time, a better quality of life [49]. How time is used in the present leads to consequences in the future, something children and young people know all too well-work hard in school, and you will be rewarded with a good job, or so the story goes. Featherstone [8] argues that the aged body is inscribed with the passing of time which serves as a reminder of our own mortality. This, he argues, is something we try to disguise through bodywork, maintenance and repair. Whereas children and young people are encouraged to use their time productively, in order to ensure a 'good' future, our desire for youthful looks is perhaps a desire to put off mortality, to suspend time.

Embodiment is fundamental to our conceptions of time. Time, embodiment and time's ability include and exclude is a notion being explored within CDS. Resting upon the argument that disability is not 'fact' but a social construction, Ferris [50] argues that disability is always mediated, and that "one crucial mediation of it, is time". Neither then, is time a 'fact'. Michalko [51] writes of "culture standard time" - the time we are all expected to adhere to, the time of the normates, the ideals, the 'ordinary man'. As a blind man, Michalko writes of "feeling dorky" using a white cane to navigate his way around (a risk, he maintains, we all face when entering a different time zone). Although 'blind time' and 'culture standard time' are expected to synchronize with one-another, the assumption of sightedness means a blind person acting within 'culture standard time' risks "looking dorky". Never-the-less, blind people are expected to 'fit in'- to synchronize their watches with 'culture standard time'. Refusing to do that, however, blindness time offers, a "time for sight, for normalcy, to develop self-understanding" - a chance for us to rethink our conceptions of time. Others make similar arguments under the term 'crip time'. 'Crip time' is not just about allowing extra time, working within a discourse of inclusion which also allows for exclusion [52-54], but about flexibility and the questioning of normative and ableist time frames [53]. Disability illuminates and allows us to challenge what has become inherent.

Classrooms are a stark example of unquestioning (and largely unquestioned), normative timeframes, which add to the educational exclusion of disabled children [53]. Although not 
specifically engaging with disability, James [55] points to the continued influence of developmental psychologists such a Piaget in the structuring of children's lives to argue that children's bodies are defined by the passing of time. She cites the most obvious example being schools organized into agebased classes. However, children do not understand the relationship between their bodies and time as purely quantitative. Rather, age (the measure of time we apply to living things) is conceptualized as a holistic, embodied experience, which symbolizes social status, and allows or denies access to any number endeavors [55]. The following quote from fieldwork with primary aged children illustrates this:

"CAROL: (after comparing her height to Lorna) I'm bigger

ALLISON [researcher]: Would you like to be tall?

CAROL: Yeah... I want to be 15

ARTHUR: Your birthday is before mine

GEORGE: Yeah, I'll be 6 and I'll be bigger than you then" ([55], p. 29)

Children come to know their bodies through the passing of time. The discussion of time, therefore, leads to one of bodies and embodiment. Aging is interwoven with ideas of bodily capability and normality: as well as learning that time has a 'value' in the classroom, children also get taught that a 'good' body is "both controlled and seen to be controllable" ([55], p. 31). The 'good' student in the classroom has the body that walks properly, sits up straight, does not fidget, ties its shoelaces and tucks in its shirt; the older the child, the higher the expectation to have a 'good' classroom body. In concurrence with feminist-disability critiques of idealized bodies, we see process of judging the interior of the body by its exterior beginning in school, and children are aware of this [56-58]. Discourses of 'good' bodies work alongside ableist discourses of 'normal' and 'healthy' bodies, and, through these discourses, children learn the cultural importance of bodywork. James [55] explains this with the example of children's conception of a 'fat' body. A fat body is not just an unhealthy body, but also a greedy body, one that eats too much, one that is not properly controlled. Bodies must be orderly. A fat body cannot tie its shoelaces or walk properly, so it is not a good orderly classroom body. Bodies must also be able to participate. A fat body cannot run fast, it gets caught playing tag, so it is not a good participating playground body. Fat bodies, therefore, are undesirable. Children, like adults, James argues, judge bodies in moral terms, although a tall body signifies age and maturity, a fat body is equated with lack of bodily control, greed and antisocial behavior.

Children and disabled people, it seems, are similarly aware of the importance of embodiment in relation to time, and its ability to include and exclude. Literature considering the sociology of the body and the sociology of childhood has scarcely engaged with disability and experiences of disabled bodies. Although not conceptualizing it as such, Chandler does just this from within CDS when she writes about her Mum telling her, her "first story of disability":

"My story of her story goes like this: When I was 5 years old I went to a friend's birthday party at the zoo. A group of girls were showing off their newly discovered skill of doing a cartwheel. As I began the dismount into this ellipse, I expected to complete it without trouble like the girls before me. Instead of gracefully spinning forward as was previously demonstrated by my friends, my wrists buckled under my weight, my legs refused to fly upwards, and I collapsed in a laughable heap on the grass in front of them. In this moment 
I understood my body as troubling but I did not have an idea of, and thusly did not have, a disability. Later that night, as my mom was helping me get ready for bed, I asked: "Mom, why can't I do a cartwheel?" expecting she would be able to untangle the entanglement that was my experience of my embodiment. She responded with the first telling of disability." [59]

Chandler's story illustrates time's mediation of disability [50]: she was not disabled until after she had "understood her body as troubling", at which time she was told of disability. Chandler's story also shows that disability's invisibility within the sociology of the body and childhood is conspicuous; it is easy to see how James' [55] explorations of 'fat' bodies with children could be replaced with a disabled body, resulting in similar (and arguably more demonizing) conceptions. Furthermore, as the majority of research considering time/embodiment relationships stems from CDS and the sociology of childhood, it seems children and disabled people are perhaps more enlightened than their adult and non-disabled counterparts in realizing the exclusionary potential of this relationship.

Christensen's [56] exploration of cultural constructions of childhood vulnerability, and Backett-Milburn's [58] study of adult and child perceptions of 'healthy bodies' concur with James: children, like adults, make internal judgments about a person, based on their external appearance. Furthermore, both children and adults are aware of the importance of 'body work' in order to maintain healthy (read: 'controlled', 'orderly', 'moral', 'good') bodies. However, whereas for adults 'body work' is done self-consciously, and both under and over attention to bodily maintenance open to criticism, for children the reason is more pragmatic, "exercise had strong and immediate purposes of social inclusion, pleasure, personal credibility and peer acceptance" ([58], p. 97). A well-exercised body can take part, it does not get caught in tag, it can do cartwheels. Similarly, Christensen [56] found, when considering the difference in how children and adults conceptualize illness, that children considered illness in relation to their world: having a cold, for example, was about not going swimming, staying inside and watching television. Adults, on the other hand, wanted to establish an 'object reality' when a child was hurt: splitting the body into 'parts' in order to locate which 'bit' required attention. Caring for the external surface of a child's body is seen as a route to the internal, the outer layer of a child's body considered more permeable than the harder shell of an adult, and a child's problems able to be cared for from the outside-in (in juxtaposition to adult problems which, according to Backett-Milburn [58], are presumed to stem from the psychological). Furthermore, the child's body was read as a reflection of the entire family: a well-presented child's body, a sign of adult parental achievement. Although the ideal body may always be young, the young, like the aged body, is expected to work to meet ideals.

\section{Youth Means Beauty Means Health}

So, how does this relate to youth and earlier explorations of idealized bodies? From the above discussion we see children and adults are equally aware of an expectation of self-governance and duty of bodily care, and as feminist critiques of fashion industries showed earlier, young people (sitting somewhere between child and adult) are far from being outside the disciplining discourses. For adults, there is an expectation not to just govern their own bodies, but to maintain the bodies of their children, and encourage children to carry out their own bodywork. Children come to know, judge and rate their own and each other's bodies (and minds) by external appearance. A further discourse of time 
permeates this: whereas children's bodies are conceived to age positively (getting bigger and stronger), adult's bodies age negatively (becoming more susceptible to illness and losing capabilities) [58], the older the body, the stronger the discourse of economic, social and physical decline [60]. Somewhere between the two is the ideal: an ideal children strive for in their growing up (bigger, taller, stronger) and adults strive for in their attempts to pause time (through purchasing anti-ageing, 'beautifying' products), the ideal of a youthful body. We are left, therefore, with three intertwining discourses: those of youth, beauty and health. Bodily maintenance is about standards of beauty. Yet, children and young people are taught that performing bodywork is a matter of health. Health, however, becomes a term that discursively stands for, and implicitly comes to mean, much more than just the efficient functioning of body parts. If, as Garland-Thomson ([15], p. 4) argues, disability acts "as a synecdoche for all forms that culture deems non-normative", youth for sale, I am suggesting, makes youth a synecdoche of for both health and beauty - forms that culture dangerously deems normative.

If youth for sale signifies the idealized, normative qualities of youth, where does this leave non-normative youth? If to be youthful is to be beautiful and healthy, what does this mean for disabled young people? Despite the old cliché, 'beauty is in the eye of the beholder', we have seen that there are strong cultural conventions around what is 'beautiful'. This, combined with arguably even stronger medical and cultural discourses about what is 'healthy' may, to use Shildrick's [18] term, leave those 'differently embodied' in a paradoxical position: although adulthood is wrapped up in a rhetoric of ableism [1], which alongside an ideology of paternalism surrounding disability leads to the infantilizing of disabled people, and their positioning as forever young; there is simultaneously an idealized discourse of youth which leaves little space for human diversity. Baron, Riddel and Wilson [61] ironically quip that disabled people hold the secret of eternal youth. In this sense, disability is perhaps the counterpart of Blatterer's [3] ideal of being youthful, but not adolescent. Disability Studies scholars have highlighted that we will all become disabled if we live long enough [14,62]. Take this assertion alongside Featherstone's [8] argument that striving for a youthful body is an attempt to deny our own mortality, and we could argue that the desire for eternal youth is an attempt to disavow disability. Of course, this is not the lived reality of dis/abled young people's lives, rather, it is an example of the abstraction of youth, leading to the enfreakment of young people that do not meet the conventions of 'youth for sale'. Youth for sale stands as a synecdoche for health and beauty. Furthermore, health and beauty are arguably the promise and want of youth that we are encouraged to strive towards in our own aesthetic projects.

\section{Conclusions: The Want and Promise of Youth for Sale}

I have argued that youth has been abstracted into a commodity to be sold in beauty markets. Considering youth as the end goal of an aesthetic project, I have drawn on feminist-disability discussions of idealized bodies to argue that discourses of youth for sale (read, beauty and health), perhaps stand in opposition to dominant discourses disability. At the beginning of the paper I drew on the work of Mallett and Runswick-Cole [9] to ask: who produces youth? What want is youth satisfying? And what is the promise of youth? I argue that beauty and related markets are one producer of the youth-thing. The want of these industries is profit, and they satisfy this want by maintaining an unattainable ideal which they claim can be bought through their products. The abstracted form of 
'youth' (for sale) has come to represent this ideal. As we have seen, both mind and quality of life judgments are made from the exterior of the body. Meeting the youth-ideal, therefore, promises not just beauty, but also health and 'the good life'. Youth in this thing-like-form is both oppressive and dangerous, marking bodies (and minds) that do not meet the youth-ideal as deficient, deviant and ultimately, disposable. Disabled bodies are perhaps the most deficient, deviant and disposable of them all. Furthermore, when youth means beauty means health, there comes an added expectation on those who are chronologically young to comply with this, and an enfreakment of those who do not/cannot/will not. Not wanting to oversimplify the situation, however, I also maintain that this is only one part of many intertwining, overlapping and contradictory discourses of 'youth' and 'disability' - disability is certainly not a phenomenon immune to market abstraction and fetishisation [9] and, importantly, young and disabled people are continually (re)producing their own, dynamic 'youth-/dis/ability-thing(s)'. However, in a competitive, take-no-prisoners, neoliberal political climate it is essential to be mindful of overarching and oppressive discourses which become implicit in our day-to-day thinking yet can, and do, prove fatal [32,33,63].

\section{Acknowledgments}

Thank you to Dan Goodley, Rebecca Lawthom, delegates at the BSA Postgraduate Disability Research Conference and Theorizing Normalcy and the Mundane 2011, and the anonymous reviewers for the useful feedback on drafts of this paper.

\section{References and Notes}

1. Slater, J. Playing grown-up: using critical disability perspectives to rethink youth. In Youth: Responding to Lives-An International Handbook; Azzopardi, A., Ed.; Sense Publishers: Boston, MA, USA, fc. 2013.

2. Wyn, J.; White, R. Rethinking Youth; Sage: London, UK, 1997.

3. Blatterer, H. The Changing Semantics of Youth and Adulthood; Cult. Sociol. 2010, 4, 63.

4. Priestley, M. Disability: A Life Course Approach; Bridge Press: Cambridge, UK, 2003.

5. Wyn, J.; White, R. Negotiating social change. Youth Soc. 2000, 32, 165-183.

6. Heiss, S.N. Locating the Bodies of Women and Disability in Definitions of Beauty: An Analysis of Dove's Campaign for Real Beauty. Disabil. Stud. Q. 2011, 31, http://www.dsqsds.org/article/view/1367/1497.

7. Shalma, M. Resistance Training: Re-reading Fat Embodiment at a Women's Gym. Disabil.Stud. Q. 2008, 28, http://www.dsq-sds.org/article/view/150/150.

8. Featherstone, M. The Body in Consumer Culture. Theor. Cult. Soc. 1982, 1, 18-33.

9. Mallett, R.; Runswick-Cole, K. Commodifying Autism: The Cultural Contexts of 'Disability' in the Academy. In Disability and Social Theory; Goodley, D., Hughes, B., Davis, L.J., Eds.; Palgrave MacMillan: Basingstoke, UK, 2012; pp. 35-51.

10. Burman, E. Deconstructing Developmental Psychology; Routledge: Hove, UK, 2008.

11. Giroux, H. Youth in a Suspect Society: Democracy or Disposability? Palgrave Macmillan: New York, NY, USA, 2009. 
12. Barber, B.R. Consumed: How Markets Corrupt Children, Infantilize Adults, and Swallow Citizens Whole; W.W. Norton \& Company: New York, USA, 2007.

13. Hughes, B.; Russell, R.; Paterson, K. Nothing to be had 'off the peg': Consumption, identity and the immobilization of young disabled people. Disabil. Soc. 2005, 20, 3-17.

14. Butler, J. Gender Trouble: Feminism and the subversion of identity; Routledge: New York, 1990.

15. Garland-Thomson, R. Integrating disability, transforming feminist theory. NWSA J. 2002, 14, 1-32.

16. Meyer, B. Extraordinary stories: Disability, queerness and feminism. NORA-Nordic J. Fem. Gend. Res. 2002, 10, 168-173.

17. Butler, J. Bodies That Matter: On the Discursive Limits of "Sex"; Routledge: London, UK, 1993.

18. Shildrick, M. Dangerous Discourses of Disability, Subjectivity and Sexuality; Palgrave Macmillan: New York, NY, USA, 2009.

19. Shakespeare, T. Cultural Representation of Disabled People: Dustbins for disavowal? In Disability Studies: Past Present and Future; Barton, L., Oliver, M., Eds.; The Disability Press: Leeds, UK, 1997; pp. 217-233.

20. Crow, L. Including all of our lives: Renewing the social model of disability. In Exploring the Divide; Barnes, C., Mercer, G., Eds.; The Disability Press: Leeds, UK, 1996; pp. 55-72.

21. .Morris, J. Personal and Political: A feminist perspective on researching physical disability. Disabil. Handicap Soc. 1992, 7, 157-166.

22. Morris, J. Feminist, Gender and Disability; Leeds Disability Archive: Leeds, UK, 1998.

23. Thomas, C. Female Forms: Experiencing and Understanding Disability; Open University Press: Buckingham, UK, 1999.

24. Hall, S.; Jefferson, T. Resistance through Rituals: Youth Subcultures in Post-war Britain, 2nd ed.; Routledge: Oxon, UK, 2006.

25. Reeve, D. Negotiating psycho-emotional dimensions of disability and their influence on identity constructions. Disabil. Soc. 2002, 17, 493-508.

26. Titchkosky, T. Governing Embodiment: Technologies of Constituting Citizens with Disabilities. Can. J. Sociol. 2003, 28, 517-542.

27. Campbell, F.K. Contours of Ableism: The Production of Disability and Abledness; Palgrave Macmillan: Basingstoke, UK, 2009.

28. Soley-Beltran, P. Modelling Femininity. Eur. J. Wom. Stud. 2004, 11, 309-326.

29. Lakoff, R.T.; Scherr, R.L. Face Value: The Politics of Beauty; Routledge: London, UK, 1984.

30. Foucault, M. Discpline and Punish—the Birth of the Prison; Pantheon Books: New York, NY, USA, 1977.

31. Turner, B.S. The Discourse of Diet. In The Body: Social Process and Cultural Theory, 3rd ed.; Featherstone, M., Hepworth, M., Eds.; Sage: London, UK, 1993; pp. 157-171.

32. Bordo, S. Unbearable Weight, Feminism, Western Culture and the Body; University of California Press: Berkeley, USA, 1993.

33. Fallon, P.; Katzman, M.A.; Wooley, S.C. Feminist Perspectives on Eating Disorders; The Guilford Press: New York, USA, 1994.

34. Blond, A. Impacts of exposure to images of ideal bodies on male body dissatisfaction: A review. Body Image 2008, 5, 244-250. 
35. Frost, L. Doing Bodies Differently? Gender, Youth, Appearance and Damage. J. Youth Stud. 2003, 6, 53-70.

36. Oberg, P.; Tornstam, L. Body images among men and women of different ages. Ageing Soc. 1999, 19, 629-644.

37. Paxton, S.J.; Wertheim, E.H.; Gibbons, K.; Szmukler, G.I.; Hillier, L.; Petrovich, J.L. Body image satisfaction, dieting beliefs, and weight loss behaviors in adolescent girls and boys. J. Youth Adolesc. 1991, 20, 361-379.

38. Carrigan, M.; Szmigin, I. Advertising in an ageing society. Ageing Soc. 2000, 20, 217-233.

39. Cartner-Morley, J. The rise of older models. The Guardian, 13 July 2010.

40. Channel 4. How to Look Good Naked. Avaiable online: http://www.channel4.com/programmes/ how-to-look-good-naked (accessed on 21 Feburary 2011).

41. Dove. Dove Campaign for Real Beauty. Avaiable online: http://www.dove.co.uk/cfrb/selfesteem-fund.html (accessed on 21 Feburary 2011).

42. Channel 4. Beauty and the Beast: The Ugly Face of Prejudice. Avaiable online: http://www.channel4.com/programmes/beauty-the-beast-ugly-face-of-prejudice (accessed on 23 Feburary 2011).

43. Mangan, L. It is parents who can't face disability on TV. The Guardian, 24 February 2009.

44. BBC News. Disabled Woman Sues Clothes Store. BBC News, 24 June 2009.

45. Sanie, E. Now you see it, now you don't. The Guardian, 5 September 2009.

46. Hevey, D. The Creatures Time Forgot: Photography and Disability Imagery; Routledge: London, UK, 1992.

47. Grosz, E. Volatile Bodies: Towards a Corporeal Feminism; Indiana University Press: Bloomington, USA, 1994.

48. Christensen, P.; James, A.; Jenks, C. 'All We Needed to do was Blow the Whistle': Children's Embodiment of Time. In Exploring The Body; Cunningham-Burley, S., Backett-Milburn, K., Eds.; Palgrave: Basingstoke, 2001; pp. 201-222.

49. Adam, B. Time and Social Theory; Polity Press: Cambridge, UK, 1990.

50. Ferris, J. In (Disability) Time. Disabil. Stud. Q. 2010, 30, http://www.dsqsds.org/article/view/1292/1328.

51. Michalko, R. What's Cool About Blindness? Disabil. Stud. Q. 2010, 30, http://www.dsqsds.org/article/view/1296/1332.

52. Titchkosky, T. The Not-Yet-Time Of Disability In The Bureaucratization Of University Life. Disabil. Stud. Q. 2010, 30, http://www.dsq-sds.org/article/view/1295/1331.

53. Price, M. Mad at School: Rhetorics of Mental Disability and Academic Life; The University of Michigan Press: Michigan, USA, 2011.

54. Titchkosky, T. Reading and Writing Disability Differently: The Textured Life of Embodiment; University of Toronto Press: Toronto, Canada, 2007.

55. James, A. Embodied Being(s): Understanding the Self and the Body in Childhood. In The Body, Childhood and Society; Prout, A., Ed.; Macmillian Press Ltd: Basingstoke, UK, 2000; pp. 19-37.

56. Christensen, P. Childhood and the Cultural Constitution of Vulnerable Bodies. In The Body, Childhood and Society; Prout, A., Ed.; Macmillan Press: Basingstoke, UK, 2000; pp. 38-59. 
57. Burnett, K.A.; Holmes, M. Bodies, Battlefields and Biographies: Scars and the Construction of the Body as Heritage. In Exploring the Body; Cunningham-Burley, S., Backett-Milburn, K., Eds.; Palgrave: Basingstoke, UK, 2001; pp. 21-36.

58. Backett-Milburn, K. Children, Parents and the Construction of the 'Healthy Body' in Middle-Class Families. In The Body, Childhood and Society; Prout, A., Ed.; Macmillan Press: Basingstoke, UK, 2000; pp. 79-100.

59. Chandler, E. Sidewalk Stories: The Troubling Task Of Identification. Disabil. Stud. Q. 2010, 30, http://www.dsq-sds.org/article/view/1293/1329.

60. Biggs, S.; Powell, J.L. A Foucauldian Analysis of Old Age and the Power of Social Welfare. $J$. Aging Soc. Pol. 2001, 12, 93-112.

61. Baron, S.; Riddel, S.; Wilson, A. The Secret of Eternal Youth: Identity, risk and learning difficulties. Br. J. Sociol. Educ. 1999, 20, 483-499.

62. Davis, L.J. Bending over Backwards: Disability, Dismodernism, and Other Difficult Positions; New York University Press: New York, NY, USA, 2002.

63. Boffey, D. Disabled people face abuse and threats of violence after fraud crackdown. The Observer, 15 May 2011.

(C) 2012 by the author; licensee MDPI, Basel, Switzerland. This article is an open access article distributed under the terms and conditions of the Creative Commons Attribution license (http://creativecommons.org/licenses/by/3.0/). 